\title{
DESIGNING WHITE WATER SLALOM COURSES FOR OLYMPIC GAMES
}

\author{
J. Pollert jun. ${ }^{1 *}$, J.Pollert sen. ${ }^{1}$, V. Strogonov ${ }^{1}$, O.Švanda ${ }^{1}$ \\ ${ }^{1}$ České vysoké učení technické v Praze, Fakulta stavební, Katedra zdravotního a ekologického inženýrství, Thákurova 7, 16629 \\ Praha 6, (jaroslav.pollert, jaroslav.pollert.2, Vadim.strogonov, ondrej.svanda)@cvut.cz;
}

\author{
Commission V, WG V/7
}

KEY WORDS: Olympic Games, artificial slalom courses, hydraulics, turbulent flow, modelling, whitewater sports

\begin{abstract}
:
The article provides an analysis of hydraulic technical requirements based on model investigations of the artificial slalom courses designed for the Tokyo 2020 Olympic Games. A main, "Competition Course" will be used for top level sporting events such as the Olympic Games, World Championships and/or World Cups, as well as commercial rafting and other recreational activities in Legacy. A second "Training Course" will be used for pre-race warmup, as well as for post-Games recreation and training opportunities for all varieties of whitewater enthusiasts, including youth development and instructional programs. The main aim of the physical model investigations was to evaluate these courses designs from a hydraulic point of view - to validate technical performance objectives and to determine the optimal positioning for hydraulic features within the channels, with respect to design criteria which are: optimal water depth at prescribed flows, optimal current velocities, optimal Games-ready hydraulic configurations, safety criteria compliance, suitability for various Legacy uses (per IOC intent).
\end{abstract}

\section{INTRODUCTION}

Whitewater canoe slalom sport at both competitive and recreational levels depends not only on the provision of top quality slalom courses (like Olympic Games) but also on the availability of local practice areas. It is important that sites that have potential for development as artificial slalom courses are identified, so that a coherent pattern of their development can enhance the canoe sport. The first great success with artificial slalom course was in Augsburg, Germany, for the 1972 Olympic Games. With a similar principle of creating an artificial whitewater course is possible to see nowadays many successful facilities in the world including all Olympic Games since 1992.

What does the term "artificial canoe slalom course" mean? In most developed countries there are very few rivers that are completely natural. Many canoe slalom sites have been enhanced by repositioning material in the river bed and providing paths and roadways for access. The term "artificial slalom course" applies specifically to sites where major works provide a facility for the canoeist where previously none existed, or where the work completely transforms the water quality of the site from sport point of view. It is an attempt to re-create the natural hydraulic phenomena found in open river basins in an artificial, purposebuilt river basin. These artificial courses can often be constructed within a short period of time, as opposed to their natural counterparts built over millions of years, and be operated with unnaturally predictable and controlled conditions.

Relative to the success of other individual sport disciplines included in the Summer Olympic Games program, Canoe Slalom has always enjoyed one of the highest ratings among international TV viewers (third highest of all sports during the Sydney 2000 Games, (Pollert, J. 2001), with similar popularity during Athens 2004, Beijing 2008 and London 2012). The excitement of the sport has proven particularly in Tokyo the 2020/2021 Olympic Games.

\footnotetext{
* Corresponding author
}

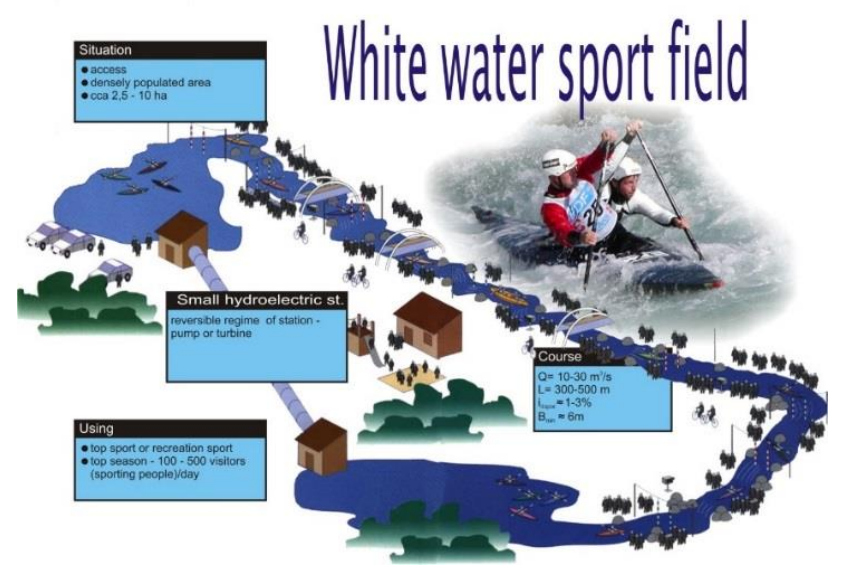

Figure 1. Basic description of whitewater courses.

\section{WHITEWATER CANOEING - THE SCIENCE BEHIND THE SPORT}

There are many economic and social benefits to the development of urban cantered whitewater parks. These parks can provide the means for professional paddling training/competition, provide the facilities necessary to host Olympic Games/top international competition, promote active recreation, attract tourists, and provide economic returns.

The success of these parks, in part, lies in their ability to serve the needs and desires of multiple different user groups. Promote whitewater sport, generally defined - whitewater canoeing, kayaking, rafting, or even inner tubing - has become one of the major growth sports among adrenaline sports. Thus, creating more facilities for people living in densely populated areas makes a lot of sense, as it increases the opportunities for participating in an outdoor sports. Increase the popular appeal of canoe slalom by giving it more exposure to large numbers of spectators and 
television audiences. Normal competitions, being held in remote, wilderness areas are hard to get to and thus do not attract large numbers of spectators and media coverage.

The Whitewater Canoe Course shall meet the all requirements set out in the, ICF (International Canoe Federation) Technical Specifications and for Olympic Games shall be in accordance with the IOC (International Olympic Committee) Technical Manual on Venues. The quality of the whitewater is to be of a standard suitable for Olympic and future international level whitewater canoeing events, while providing a robust legacy for the sport. The performance specifications relate to those aspects that are required for the delivery of dynamic whitewater as an acceptable finished product in the Olympic channels when the specified flow of water is supplied respectively. The quality and characteristics of whitewater in each channel shall achieve a consistent standard for all targeted uses. The Olympic whitewater channels shall be designed to effectively serve a variety of uses and user groups during both Olympic related and Legacy operations. The channels will support high-level Canoe/ Kayak Slalom training and competition prior to and during the Olympic Games. In Legacy operations, it will support a commercial rafting operation, along with a variety of recreational paddling and dedicated sport activities. As a guide, it should be designed for a minimum capacity of 15-20 rafts and approximately 40 canoes/ kayaks to utilize the course simultaneously but could potentially accommodate more depending on operational/ programming decisions

Useable construction areas controlled by the organizing city (e.g. it is often desirable to organize all the water sports at one location, if possible - rowing, flat water canoeing, and canoe slalom allowing uniform main infrastructure for all sports).

A majority of whitewater canoe slalom courses (the first one was built in Augsburg, Germany, for the Olympic Games in 1972) were traditionally copies of watercourses with a prevailing linear channel. This limited the ability of spectators to view the entire event. This was changed with the course for Sydney 2000 when the team of designers attempted opted for a more circular shape, addressing a desire to let viewers observe more of the course from the start to the finish.

\section{OPEN CHANNEL FLOW AND WHITEWATER COURSES}

Artificial whitewater canoe courses are typical examples of open man-made channel flow. An open channel flow is the flow of a liquid (water) in a channel or a conduit that is not completely filled, (Chanson 2004). A free surface exists between the flowing fluid and the fluid above it (mostly air). The main driving force is fluid weight and gravity forces driving the flow downhill.

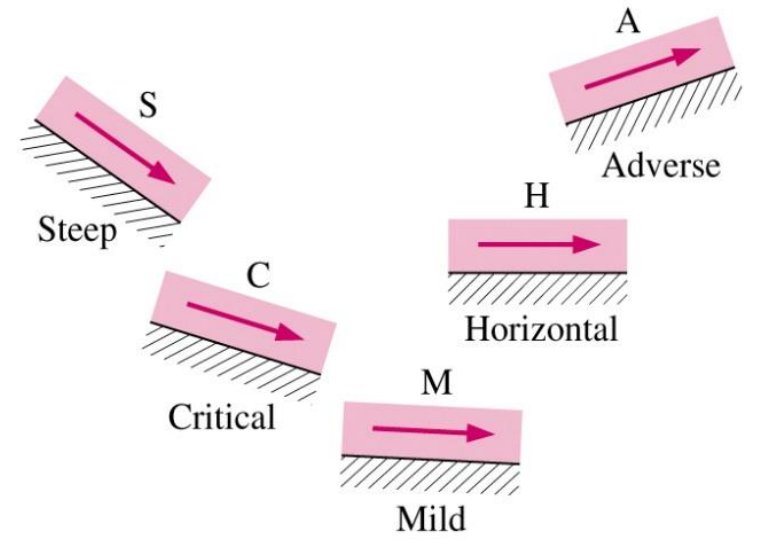

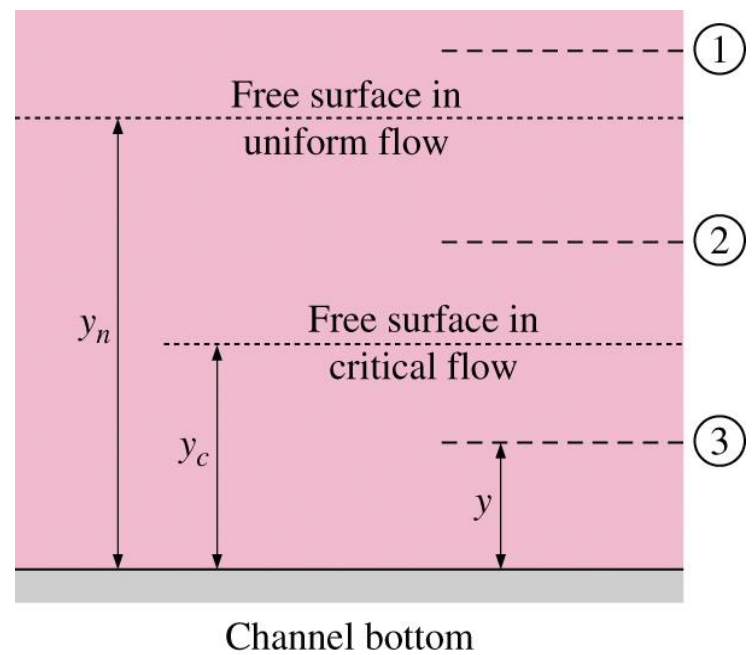

Figure 2. Channel slopes.

Analysis of hydraulic problems connected with the design shows important facts and reciprocal functions between Froude number Fr, bottom slope $i_{0}$, and water level slope if :

- Bottom slope $i_{0}$ is possible to define:
- Steep : $\mathrm{y}_{\mathrm{n}}<\mathrm{y}_{\mathrm{c}}$
- Critical : $y_{n}=y_{c}$
- Mild : $y_{n}>y_{c}$
- Horizontal $: \mathrm{i} 0=0$
- Adverse : $\mathrm{i}_{0}<0$

Decisive depth for various flow is given by:

$$
\begin{aligned}
& \text { 口 } 1: \mathrm{y}>\mathrm{y}_{\mathrm{n}} \\
& 2: \mathrm{y}_{\mathrm{n}}<\mathrm{y}<\mathrm{y}_{\mathrm{c}} \\
& 3: \mathrm{y}<\mathrm{y}_{\mathrm{c}}
\end{aligned}
$$

Artificial canoe courses should meet several criteria - high velocities, big waves, etc. for top athletes, but also appropriate and safe for recreational users. Actual volume of water moving along a course can be measured fairly accurately in $\mathrm{m} 3 / \mathrm{s}$. However, the rate of flow is a measure of its energy but does not indicate the difficulty or severity of the rapids. The ICF established International Scale of River Difficulty (I. - VI.) which is universal scale used to rate the safety or severity of rapids.

Positioning of constrictions and/or flow obstruction within the channel must maintain the flow towards the centre line of the channel. Where possible flow must not be directed into the walls of the channel nor should any single constriction or flow obstruction deflect the main flow of water from a path nominally in the centre of channel. Should any constriction deflect flow from the midline of the course then a compensating deflection must be installed to redirect and maintain the flow to the midline of the channel. Constrictions leading to the main drops must deliver the flow of water parallel with the direction of the channel and allow an area of increased depth prior to the constriction at the entrance to the drops. Eddies coincident with constriction points, the groins and obstacles will form adjacent eddies just downstream and at the side of the channel constriction. An eddy is an area of water that is contrary to the main current and often has a recirculating flow pattern within it. Typically an eddy will either have no downstream component of velocity, or it may have a measurable upstream velocity. Any resultant upstream eddy flow may be no more than $1.5 \mathrm{~m} / \mathrm{s}$. The eddies in both the Olympic channels are intended to enable canoes and/ or rafts to remain stationary at the side of the channel, out of the main current. A minimum water depth in eddies of not less than $1000 \mathrm{~mm}$ must be achieved in all areas. Throughout the Olympic channels the channel walls need to be broadened to allow for 
medium sized eddies (capable of holding several canoes/ kayaks) an upstream velocity of not greater than $1.5 \mathrm{~m} / \mathrm{s}$ should not be exceeded in any eddy.

The course should contain following important hydraulic features:

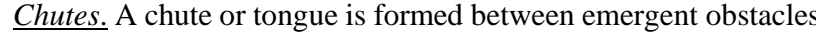
in the flow or when a course narrows. This constricting accelerates the flow water. However, once the course widens again the accelerated flow hits a pool of slower moving water. This in turn creates a wave or hole. The character of flow is called "green water", and major turbulence appears rarely or usually missing. It is usually flowing fast but is not difficult to navigate. Stoppers, or Holes. The proper hydraulic term for these is "hydraulic jump". These may form at the bottom of a chute and can literally stop a canoe. They consist of a highly turbulent, white, foaming, wave breaking in the upstream direction, and which may be sufficiently strong to prevent a canoeist from continuing his downstream passage. A canoe can be held stationary between a chute and the face of a stopper, where sometimes escape can be affected only by abandoning the canoe and diving below the stopper to be caught in the fast downstream current underneath. Stoppers may be at right angles or diagonal to the flow.

Haystacks. These will also form at the end of a chute and consist of a series of waves which are stationary relative to the banks. The surface water flows up and down, through peaks and troughs (i. e. perpendicular to the crest line) and is relatively easy to navigate unless the waves are very steep, so that the crests are erupting into whitewater.

Eddies, or reverse flow. Eddies form when the flow of water to move around an obstacle. The water velocity increases and the level is higher than the pool of water directly behind the obstacle. Because of this different in water level the current flows back toward the obstacle in an upstream direction to balance the differential in water level. This can occur when the flow is constricted through a narrow section and then expands as a jet in the centre of the stream. Between the expanding jet and the banks there may be reverse flow, i.e. the current returning upstream to the downstream side of the obstruction causing the jet.

Turbulence. Turbulence is made up of abrupt changes in flow velocity along a course which causes overall fluctuations of the average flow velocity along a course. Irregular and unstable vortices and rollers form at boundary layer but dissipate downstream.. (Pollert J., 2015)

The most widely used classifications of channel flowrate as follows: Uniform Flow, Gradually varying flow, Rapidly varying flow. Uniform flow is achieved through a balance between the potential energy lost by the fluid as it flows downhill and the energy that is dissipated through viscous effects. Gradually varying flows occur for many reasons - the gradient is not constant, the downstream section shape varies, the downstream area varies, or obstructions along the course. Rapidly varied flow occurs when the change in fluid depth is significant along a very small distance (e.g. a hydraulic jump or a sudden change in channel geometry (expansion or contraction of cross section).

The energy losses through the open channel are attributed partly to the friction of the riverbed, but there are also losses attributed to the formation and dissipation of high velocities in jets, hydraulic jumps, etc. These latter types of losses, so called "obstruction losses" would be determined separately and added to the mean friction loss. The roughness of the course surface is the most important parameter when considering the optimization of slalom course geometry and flow conditions. The critical state of flow $(\mathrm{Fr}=1)$ causes unstable phenomena. A flow at near critical depth tends to cause the water level to pulsate and to make for unsteady conditions in time and space. Thus, the critical condition of flow (critical depth, velocity corresponding to critical state, etc.) defines a lower limit. The safe height of a hydraulic jump, i.e. the corresponding local maximum of Froude number, would define an upper limit when designing courses. In all cases, it is highly recommended that model studies be made before determining a final design, from a hydraulic point of view. Slalom courses can be described by using a Froude number as the best characterization of the courses of different type and difficulty

$$
F r_{c h}=\frac{v_{s}}{\sqrt{g y_{s}}}
$$

This describes the streaming in the course as a whole. It is thus defined by the mean value of depth, width, cross section, hydraulic radius and mean longitudinal slope $\mathrm{i}_{0}=\mathrm{H} / \mathrm{l}$ (where $\mathrm{H}$ is the difference between upper and lower elevation and 1 is the course length). The mean velocity of a turbulent flow can be expressed in the well known Manning formula

$$
v_{s}=\frac{1}{n} R_{s}^{2 / 3} i_{0}^{1 / 2}
$$

The dependence of characteristic Froude number on the roughness coefficient is shown on Figure4 with mean longitudinal slopes $\mathrm{i}_{0}=0.01$ and $\mathrm{i}_{0}=0.015$, discharges $\mathrm{Q}=10$ $\mathrm{m}^{3} / \mathrm{s}$ and $20 \mathrm{~m}^{3} / \mathrm{s}$ and usual mean width $B_{\mathrm{s}}=10 \mathrm{~m}$ were taken into account (these values correspond to the common ranges of longitudinal slopes, discharges and to the width of slalom courses). From Figure 4 it is evident that the roughness is very important factor, having a strong influence on the course difficulty, (Pollert, J. 2001).

Generally, the following ranges of characteristic Froude numbers are recommended for preliminary evaluation of any course design
Novices
$1.3<\operatorname{Fr}_{\mathrm{ch}}<1.7$
Elite athletes$$
1.7<\operatorname{Fr}_{\mathrm{ch}}<2.4
$$

\section{PHYSICAL HYDRAULIC MODELLING AND WHITEWATER COURSES}

The argument for using an hydraulic physical model to design the slalom course is that alternative method of design by calculation would be virtually impossible unless very simple geometrical cross sections were adopted. Such a procedure would produce a far less natural effect and would still be open to question on the reliability of the calculations. A model on the other hand can be adjusted in the laboratory and the effects on the flow conditions observed directly.

This limited approach might produce less natural effects could leave a project open to scrutiny of the calculations. A physical model, on the other hand, can be adjusted in the laboratory and the effects of flow conditions can be observed directly. The following are specific objectives of physical models used for artificial slalom courses. Validate the basic geometry of the channel (i.e. length, width, bottom slope, location and shape of obstacles).

Develop the basic design of an entry gate and transition that would pass variable flows while maintaining a constant upstream reservoir elevation and at the same time permit safe transit of canoeists from the reservoir into the slalom channel. In cases where an entry gate is very high and safe transit of canoeists is a concern, it may be necessary to provide transition pools of sufficient length at the top of the channel. Determine the hydraulics of the channel, including how much head loss would be absorbed in the entry, in the channel itself, and at the exit. Determine the operating characteristics and control problems associated with all flow conditions, including extreme operations, to maximize safe hydraulic conditions. Develop the obstacles and banks with simple geometrically similar shapes to facilitate construction formwork and develop replaceable obstacles with simple anchoring in the bottom. To determine 
proper placement and shaping of obstacles to enable canoeists to return upstream in some parts of the channel. Provide an artificial whitewater course that can be useable under different flow conditions (i.e. for novices as well as experts).

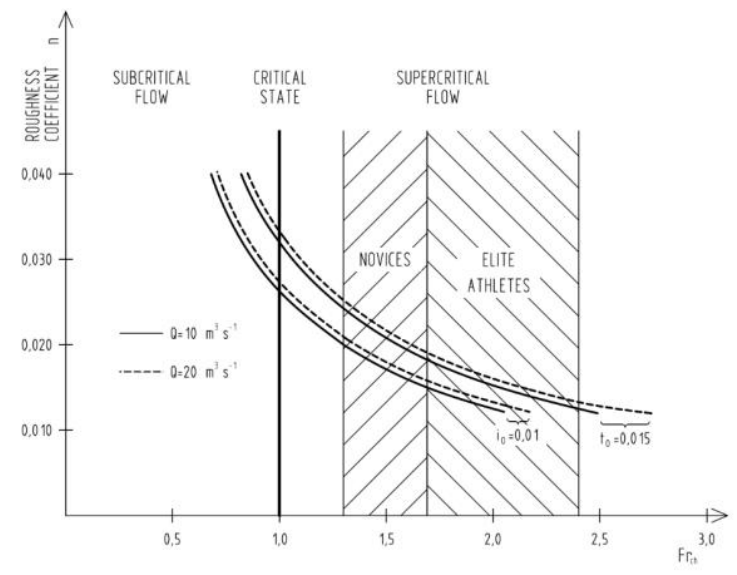

Figure 3. Relationship between friction factor and characteristic Froude number (artificial slalom courses).

The basic relevant parameters needed for any dimensional analysis may be grouped into the following classifications, (Streeter, V.L. at all., 1964):

a) Fluid properties and physical constants. These consist of the density of water $\rho(\mathrm{kg} / \mathrm{m} 3)$, the dynamic viscosity of water $\mu(\mathrm{N} \mathrm{s} / \mathrm{m} 2)$, the acceleration of gravity $\mathrm{g}(\mathrm{m} / \mathrm{s} 2)$, etc.

b) Channel (or flow) geometry. These may consist of the characteristic length $(\mathrm{s}) 1(\mathrm{~m})$.

c) Flow properties. These consist of the velocity(ies) $\mathrm{v}$ $(\mathrm{m} / \mathrm{s})$ and the pressure difference $(\mathrm{s}) \mathrm{p}(\mathrm{Pa})$.

Taking into account all basic parameters, dimensional analysis yields:

$$
\mathrm{f}(\rho, \mu, g, 1, v, \Delta p)=0
$$

In free-surface flows (e.g. rivers and wave motion), gravity effects are predominant. Model prototype similarity is performed usually with a Froude similitude

$$
F r=\frac{v^{2}}{g \cdot L}=i d e m
$$

A Froude number modelling is typically used when friction losses are small and the flow is highly turbulent: e.g. spillways, overflow weirs and flow past bridge piers, as well as could be used for whitewater courses modelling. In hydraulic structures and for wave motion studies, the gravity effect is usually predominant in prototype. The flow is turbulent, and hence viscous and surface tension effects are negligible in prototype if the flow velocity is reasonably small. In such cases a Froude similitude must be selected. The most economical strategy for modelling of slalom course is:

1. To choose a geometric-scale ratio such as to keep the model dimensions small,

2. To ensure that the model Reynolds number is large enough to make the flow turbulent at the smallest test flows.

The modelling of flow resistance is not a simple matter. Often the geometric similarity of roughness height and spacing is not enough. The flow resistance can be described in terms of the Darcy-Weisbach friction factor or an empirical Manning friction coefficient, (Streeter, V.L. at all., 1998). In summary, a physical model (based upon a Froude similitude) has proportionally more resistance than the prototype.

One of the most powerful tools in fluid mechanics is dimensional or similarity analysis, which permits a wide generalization of experimental results. Flow conditions in an open channel are generally described by the Froude number. Thus, based on previous experiences and considering the available space of the hydraulic laboratory at the Czech technical university, the scale for physical model of the Tokyo 2020/2021Olympic course was 1:13 and used the dynamical similitude (two phenomena are dynamically similar if the dimensionless form of each physical variable has the same value at corresponding points).

Open channel structures, such as artificial slalom courses, generally have gravity forces and inertial forces that far outweigh viscous and turbulent shear forces. Thus, geometric similitude and equivalency of Froude number for the model number and prototype produce a good approximation to dynamic similitude. Although the accuracy of Froude scale models is well established, their interpretation can be difficult. The main problem is that since all water levels, including heights of standing waves and other surface disturbances are reduced by the linear scale factor, this very fact makes observation difficult. A further difficulty arises in that the water surfaces of the full-size channel will have much more "whitewater" than the model. In fact, the model has very little "whitewater", whereas the full size channel will be very impressive with large areas of whitewater. This is because the white colour is produced by entrained air in the water surface and the amount of air entrained depends to a great extent on the absolute water velocity. Therefore, there will be many regions in the model where the water surface looks smooth and black, that in full-size will appear white and turbulent. The model study for some whitewater courses with relatively small number of obstacles showed that in part with higher bottom slopes (1\% and higher) would resolution high velocities and shallow depths. Tentatively, it was decided that large/higher number of obstacles would be needed on the flat concrete floor (low roughness) to control flow depths and velocities, and produce desirable current and eddy patterns.

\section{PHYSICAL AND MATHEMATICAL MODELLING OF TOKYO COURSE}

Basic geometry - the length of an artificial slalom course should conform to the standards of International Canoe Federation (ICF) from $200-400 \mathrm{~m}$, the width of $10 \mathrm{~m}$ or more is suggested for putting gates allowing manoeuvring among them, minimum depth of about $0.6 \mathrm{~m}$ is needed, since canoeists would have difficulty in paddling in shallower water; depth of $0.6 \mathrm{~m}$ of water is also so that paddlers can successfully perform an Eskimo roll; however, depths great enough should be minimized to reduce costs or necessary flow rate $\mathrm{Q}$. The second group of parameters, which apparently influence the quality and difficulty of the course, includes the discharge through the course and the bottom slope. Both are often limited; the discharge - by insufficient capacity of upstream reservoir or by low discharge in the river during the season; the bottom slope - by configuration of the ground.

There are three ways of forming hydraulic features in whitewater courses:

1. Permanent blocks, with rounded edges for safety, to constrict and divert the water flow. These should not be undercut, and their upstream surfaces should be sloped to allow the current to push boats to the surface. Like a groynes.

2. Moveable blocks temporarily secured in position so that the flow patterns within the course can be changed from 
time to time and for different standards of paddling skills. Rapids created by high velocity water falling into slowmoving water areas. They have no obstacles in them to obstruct boats or swimmers.

\subsection{Starting pool}

In this case the mathematical model was used to predict the flow in the starting basin. Mathematical modelling predicts the behaviour of the model, so after the model was build the model was confirmed. This technique predicts the behaviour of the flow without calibration or verification. This blind prediction shows the basic water flow without high precision, but enough for this. The models are in general still closer to reality than previously knowledge would predict. We are using boundary conditions from previous projects as initial values for the new one. This knowledge increases with the number of projects.
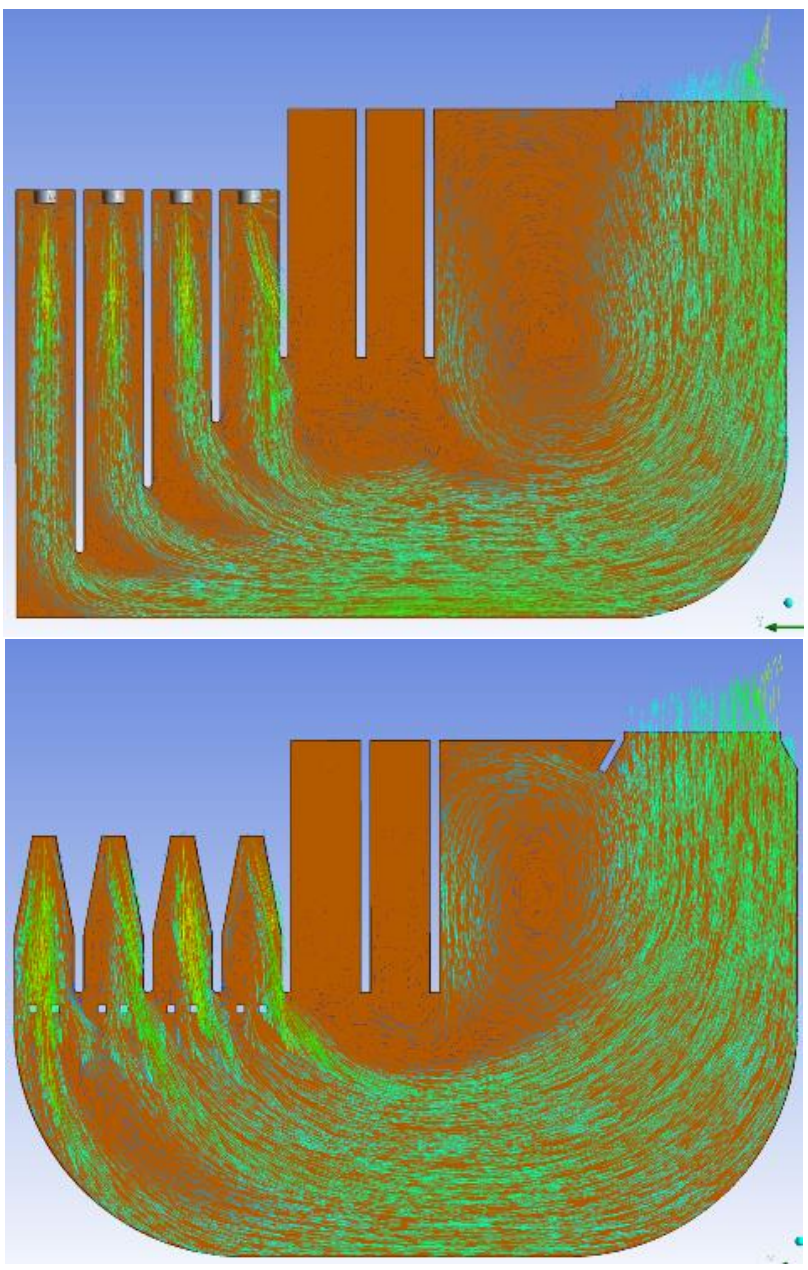

Figure 4. Starting pool geometry development.

The starting basin is used for several purposes such as:

- Outflow from the pumps

- Resting place before training or rafting

- Entry from transport belt which help users to move from the finish lake to the start lake

- Start for the competition from starting boxes

- Inflow to the course

The aim of the mathematical model were these aspects:

- Uniform flow pattern in the pool
- Uniform outflow from the pumps

- Uniform outflow from the pumps when one of them is off

- Uniform flow in the start boxes

- Uniform stream for the inflow to the course

- Calm area at the entrance part of the pool

14 versions of the start pool were done before it was built as a physical model. The main problems were with non-uniform flow when different pumps were used and the inflow to the course must be the same.

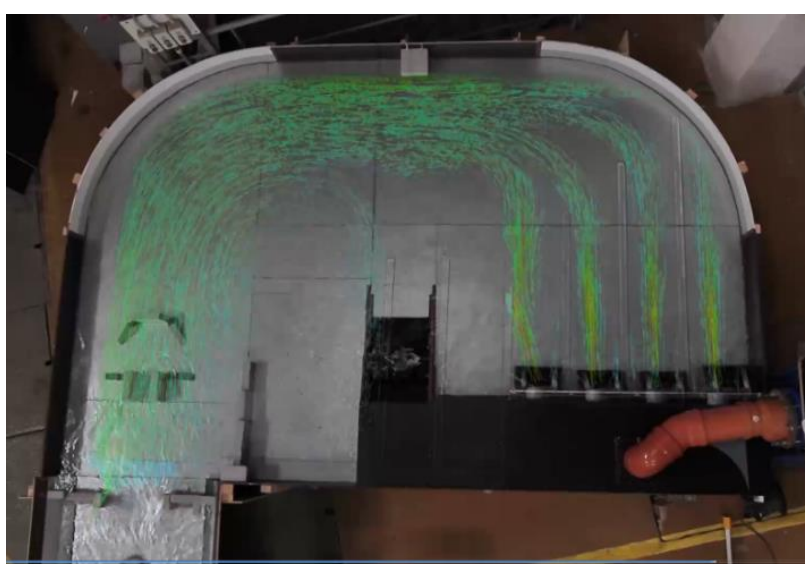

Figure 5. Final model confirmation.

\subsection{Lake}

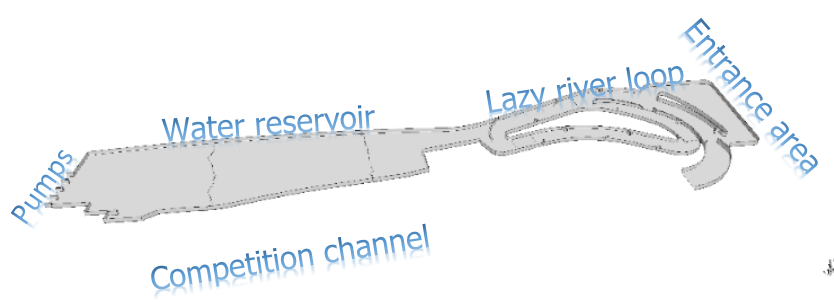

Figure 6. Overall geometry of the lake.

The main lake is primarily used as a reservoir for the water to supply the competition course. Secondarily it will be used as a training area for beginners. This is a way to increase performance and legacy benefits for the whole centre. For the training area the lazy river was developed as a loop after the main course with jets which create velocities up to $1 \mathrm{~m} / \mathrm{s}$.

The blind mathematical model was used to evaluate following criteria:

- Uniform flow pattern in the lake

- Uniform outflow to the pumps

- Uniform stream for the main current

- Calm area at the entrance part of the lake

- No flow for the lazy river part

- Helping of the flow for the lazy river part

6 versions of the lake were done before it was built as a physical model. The physical model included only the first part with lazy river. 


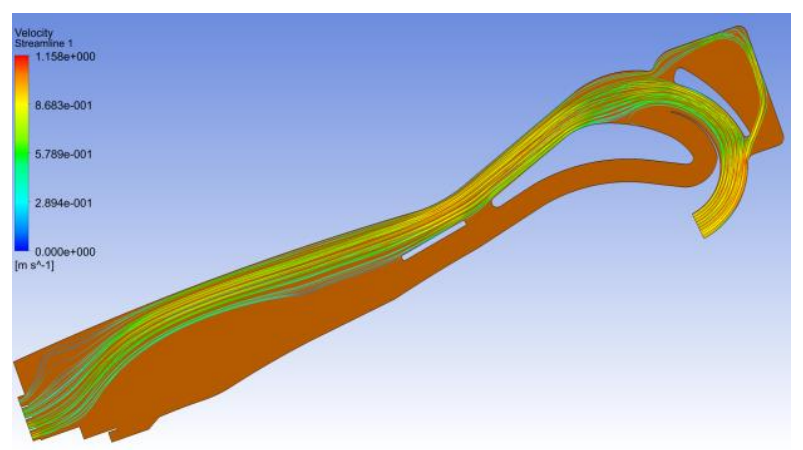

Figure 7. mathematical model of the lake.

The overall concept and design for the courses is the work of the USA based company Whitewater Parks International (WPI), who also designed the Canoe Slalom courses for London in 2012 Olympic Games. WPI commissioned Czech Technical University in Prague to conduct hydraulic experiments connected with these courses, including the construction and testing of these physical models. Each model was constructed and investigated separately.

The main objective of the model study was to build hydraulic model where be possible to modify shape of cross sections and produce the essential features for top grade slalom competitions. The secondary objective was that the course should be capable of being used by intermediate standard canoeists for training purposes. The construction of both whitewater courses was divided into sections and pools according to the design. The main aim of all investigations concentrated on finding an optimal position and size of obstacles in each section and pool with respect to functionality of hydraulic features and safety (e.g., minimum water depth $0.6 \mathrm{~m}$ ). Obstructions or "obstacles" were divided into two main groups: fixed and movable obstacles. Movable obstacles were recommended for areas where it would be possible to create flow streamline changes for varying user groups (post-Games use). Recommended positioning of these obstacles is shown elsewhere in this report.

\begin{tabular}{|c|c|c|}
\hline Scale 1:13 & $\begin{array}{c}\text { Competition } \\
\text { course } \\
\text { Reality }\end{array}$ & $\begin{array}{c}\text { Competition } \\
\text { course } \\
\text { Model }\end{array}$ \\
\hline Length $(\mathrm{m})$ & 250 & 19,23 \\
\hline Flow rate & $12,0\left(\mathrm{~m}^{3} / \mathrm{s}\right)$ & $19,69(1 / \mathrm{s})$ \\
\hline Max slope $(\%)$ & 2 & 2 \\
\hline Head $(\mathrm{m})$ & 4,5 & 0,35 \\
\hline
\end{tabular}

Table 1. Parameters of the full sized and modelled courses

The main aim of the modelling project was to find suitable locations for movable and fixed obstacles in the courses. The main criteria were described earlier, but we also utilized more detailed criteria. Our criteria were: sufficient water depth; velocities in a usable range; no fluctuating water (stable stream flow and depth); creating different characteristics in each section and pool to address different uses (whitewater slalom, rafting, rodeo and others). In each section, investigated separately and in connection to each other, we tested at least 5 different scenarios from which an optimal configuration was chosen. Both moveable and fixed obstacle positions were determined using previous experience with moving obstacles and how they influence stream flow and other important criteria.
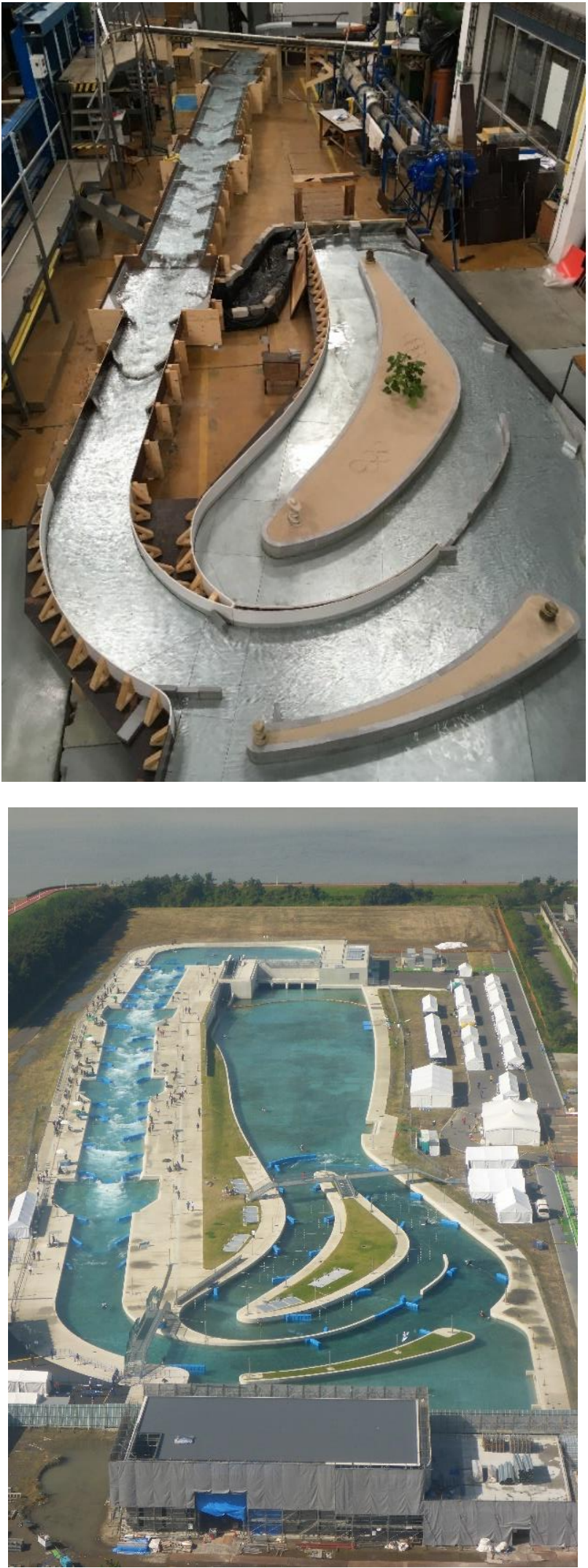

Figure 8. a,b View on laboratory model in scale $1: 13$ and finished full size Tokyo Olympic slalom course.

Basic construction material for the each model was used: 
- Water protected plywood with additional surface improvements with plastic folia extruded polystyrene for construction of banks and obstacles steel plates for channel bottom and quick changes of obstacle positions

- Magnets - each obstacle for modelling flow in the courses was equipped with $\mathrm{Nd}$ magnets.

The experiments concentrated on velocities, creation of key hydraulic features in different sections of the courses (whitewater experience of investigators was particularly useful here), depths, directions of flow, and everything else that could be influenced by the configurations of obstacles. Each measured point in the model was characterized as follows:

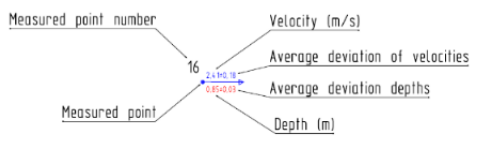

$$
\begin{aligned}
& \text { Streamlines } \\
& \cdots \cdots . . \text { Eddie } \\
& \infty 000 \text { Stopper } \\
& \text { urs Wave } \\
& \curvearrowright \nearrow \text { Streamline }
\end{aligned}
$$

Figure 9. Schematization of measurements with respect to recorded points

Discharge in the model was measured by magnetic-induction flowmeter KROHNE DN 200. Point velocities were recorded by micro propeller Greisinger Electronic GmbH, GMH 3350 (accuracy $0,01 \mathrm{~m} / \mathrm{s}$; frequency of measurement $1 \mathrm{~s}$; range $0,05-$ $5 \mathrm{~m} / \mathrm{s}$ ). Based on experience velocities were measured mostly in position $0.3 \mathrm{~m}$ (recalculated from reality) and in critical sections selected points in 3 different depths $(0.1 ; 0.3$ and $0.6 \mathrm{~m}$ below water level). Depths were measured using ultrasonic sensor Pepperl-Fuchs and thus flow was not influenced. Depths were measured upstream and downstream of each obstacle. Five different configurations of obstacles were tested in each section, from which an optimal configuration was recommended. During model construction, special attention was paid to control of model bottom roughness established by steel plates. Roughness of steel plates was measured in Carl Zeiss Metrology Centre Faculty of Mechanical Engineering, CTU in Prague. After scale recalculation roughness corresponded to Manning friction coefficient $\mathrm{n}=0.011-0.012$ (fair-face concrete). For mathematical modelling ANSYS - FLUENT CFD modelling was used.

The basic ground plan and placement of the courses in D Complex was designed by Whitewater Parks International, which while addressing all the technical requirements of IOC and ICF, also aimed to reduce construction and operating costs by $+/-30 \%$, compared with earlier iterations. Both competition and training courses are fed from a storage lake by a single pumping station. Each course in the model includes a start pool, 11 whitewater sections or pools, and a feeding lake (reservoir). Each section was investigated separately and later altogether, allowing sections to mutual influence each other. An important part of model experiments included investigating water levels in the feeding lake (it is also the finish pool of each course). It was necessary to evaluate any limitations of water levels in both start and finish pools in the courses and any impact on water levels in feeding lake.

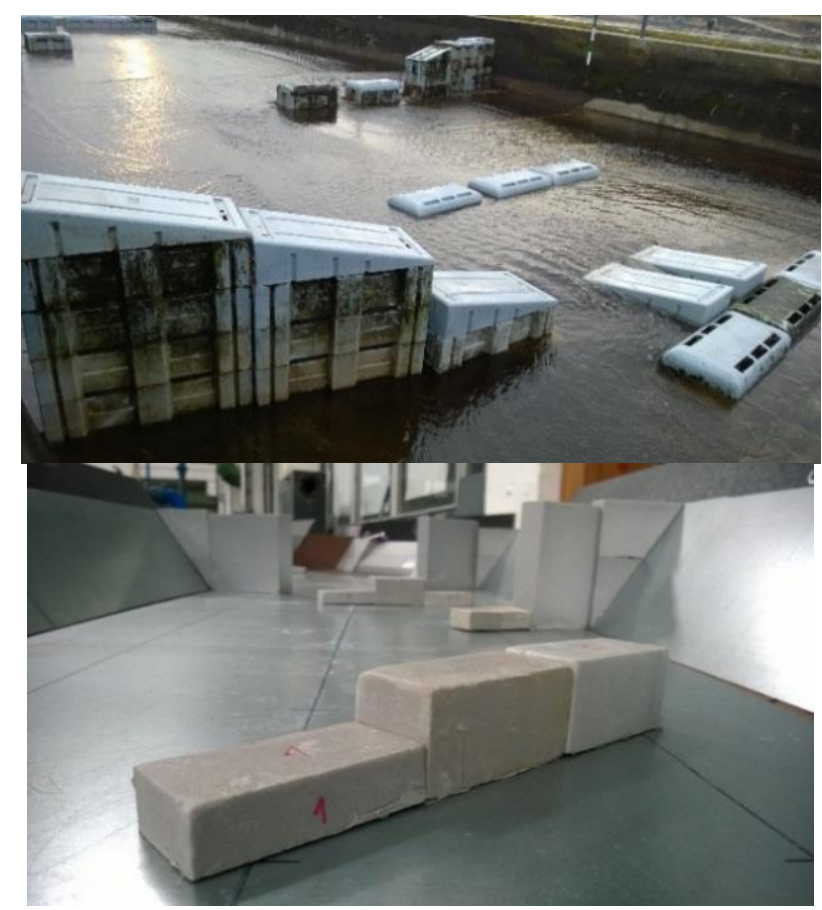

Figure 10. a, b Examples of obstacles - real life (Prague-Troja) and scaled $1: 13$ model; bottom covered with steel plates; each obstacle had Nd magnets in lower part of obstacles.
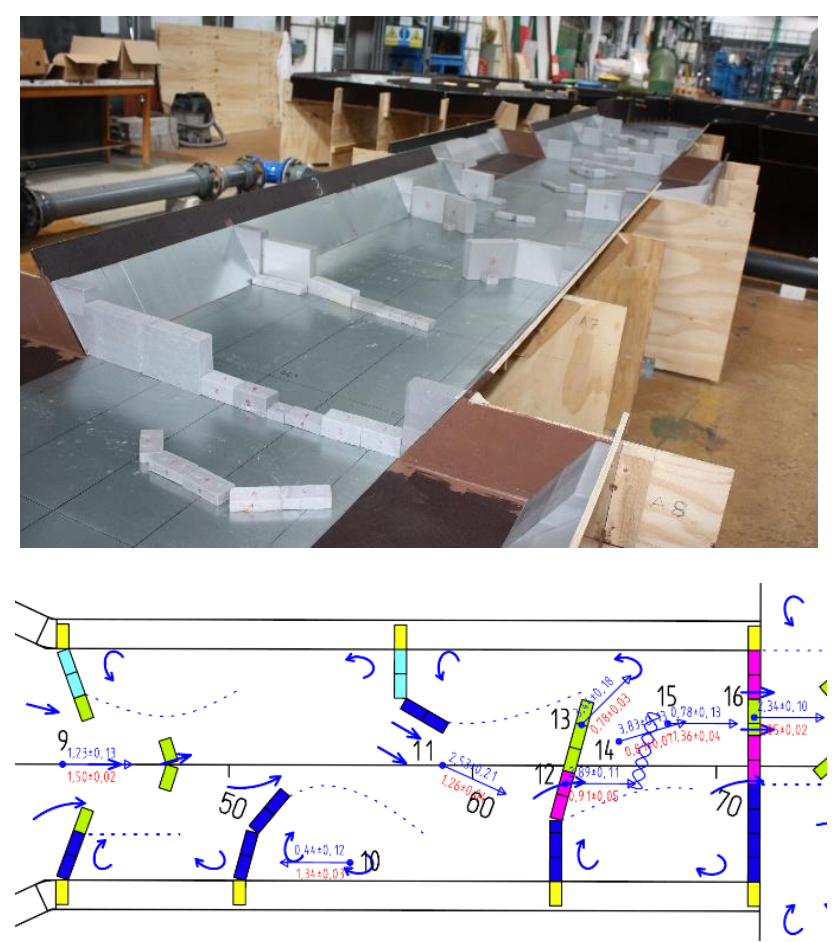


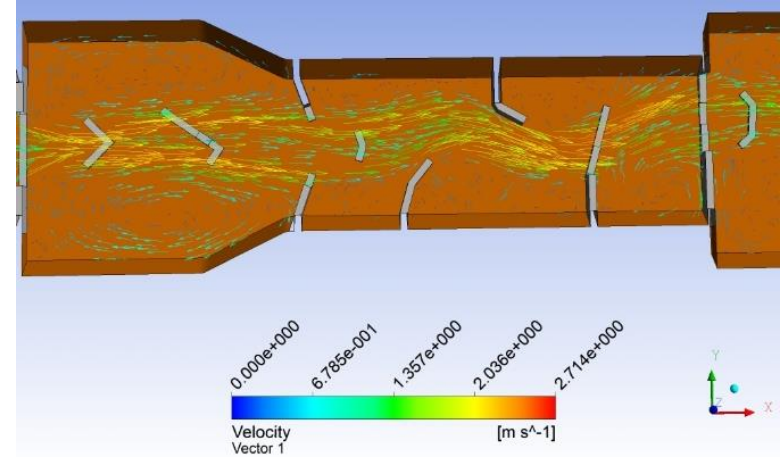

Figure 11. a, b, c Assymetric section No. 4 without and with water, map of obstacle distribution (each colour represents a different size obstacle); mathematical modelling of flow.

Competition course was investigated with two important considerations - finding the highest difficulty from a sport point of view, but with the maximum degree of safety. In the starting pool, it was challenging to direct the main flow and streamlines from the pumping outlet and to create a consistent start area for athletes. Steadiness and uniform flow at the beginning were disturbed by starting blocks (required sport equipment). The problem was solved using deflector panels at the outlet from the pumps. The problem also resolved by using higher obstacles at the pool outlet into the first section of the channel. The pool depths were approximately $1.5 \mathrm{~m}$ and flow velocities around 1 $\mathrm{m} / \mathrm{s}$ in the reality.

The water in a slalom course must be made highly turbulent through careful placement of obstacles in the course. One of the high costs is extensive hydraulic modelling to lay out the obstacle (Sydney placement lasted nearly one year it was carried in scale $1: 1$ in the empty concrete finished course). A moveable obstacle system reduces the need for extensive modelling and allows for easy tuning of the finished system according to laboratory physical modelling.

The competition course was divided into 11 sections. The following example of an investigation is section "4 asymmetric". This section could be characterized from a hydraulic point of view as a fast-meandering flow created by a combination of bigger obstacles adjacent to the bank walls and smaller submerged obstacles closer to the main current.

The main aim of the training course is to provide basic training, as well as a warmup area for the athletes during Olympic Games. Post-Games use (following IOC and ICF recommendations) will include basic instruction and training of novices and young athletes. For these purposes, the whitewater difficulty is only Grade II.-III. and in some singularities Grade IV.

\section{CONCLUSIONS}

Olympic Games in Tokyo was carried out within 5 weeks. The models in linear 1:13 scale fully addressed the main objectives: prepare a map of obstacles distribution and establish suitable whitewater characteristics according to IOC and ICF requirements. By suitable placing of obstacles which prepare suitable placing of slalom gates, a wide range of top slalom course and training course could be devised for competitions of international and national standard. Both courses are suitable for everyday training top and intermediate canoeist and training smaller course for novices at reduce flow rate. A moveable obstacle system will allow creation of all necessary hydraulic features, critical for good quality competition and safe recreation. The model demonstrated hydraulic features which can be stable while minimizing water level surging or other inconsistencies.
Hydraulic model investigation results also support future collaboration between course designers, the IOC, the ICF and host organizers of the Games in attempting to minimize construction and operation costs (see Table 2- comparison with previous Olympic facilities) and the risks associated with future projects:

\begin{tabular}{|c|c|c|c|c|c|}
\hline & $\begin{array}{c}\text { Sydney } \\
2000\end{array}$ & $\begin{array}{c}\text { London } \\
2012\end{array}$ & $\begin{array}{c}\text { Rio } \\
2016\end{array}$ & $\begin{array}{c}\text { Tokio } \\
2021\end{array}$ & Savings \\
\hline Discharge & $14 \mathrm{~m}^{3} / \mathrm{s}$ & $15 \mathrm{~m}^{3} / \mathrm{s}$ & $\begin{array}{c}12 \\
\mathrm{~m}^{3} / \mathrm{s}\end{array}$ & $\begin{array}{c}12 \\
\mathrm{~m}^{3} / \mathrm{s}\end{array}$ & $15 \%$ \\
\hline Head & $5.5 \mathrm{~m}$ & $5.5 \mathrm{~m}$ & $\begin{array}{c}4.5 \\
\mathrm{~m}\end{array}$ & $4.5 \mathrm{~m}$ & $18 \%$ \\
\hline Length & $320 \mathrm{~m}$ & $300 \mathrm{~m}$ & $\begin{array}{c}280 \\
\mathrm{~m}\end{array}$ & $\begin{array}{c}280 \\
\mathrm{~m}\end{array}$ & $13 \%$ \\
\hline Width & $12 \mathrm{~m}$ & $10 \mathrm{~m}$ & $\begin{array}{c}9.5 \\
\mathrm{~m}\end{array}$ & $9.5 \mathrm{~m}$ & $21 \%$ \\
\hline
\end{tabular}

Table 2. Possible savings in construction of Olympic Games white water facilities; similar difficulty of the course from canoeists point of view.

\section{REFERENCES}

Chanson, H., 2004: The Hydraulics of Open Channel Flow: An Introduction. Elsevier Publishing

Pollert, J. 2001: Vodní stavitelství a Olympijské hry v Sydney 2000 - Penrith Whitewater Stadium. (Water structures and Olympic Games 2000 - Penrith Whitewater Stadium), Vodni hospodářství, 51(4), 90-91.

Streeter, V.L. 1964: Hanbook of Fluid Dynamics. First Edition Mc Graw-Hill Book Company, Inc. ,

Streeter, V.L., Wylie, E.B., Bedford, K.W. 1998: Fluid Dynamics. Nith Edition, Mc Graw-Hill Book Company, Inc,

Pollert, J.; Pollert, J.; Procházka, J.; Chmátal, P.; Campbell, B.; Felton, J.; Dungworth, D., 2015, Physical and Mathematical Modelling for Canoe Slalom Whitewater and the 2016 Olympic Games in Rio de Janeiro, 14th International Symposium on Water Management and Hydraulic Engineering., Littera Brno 